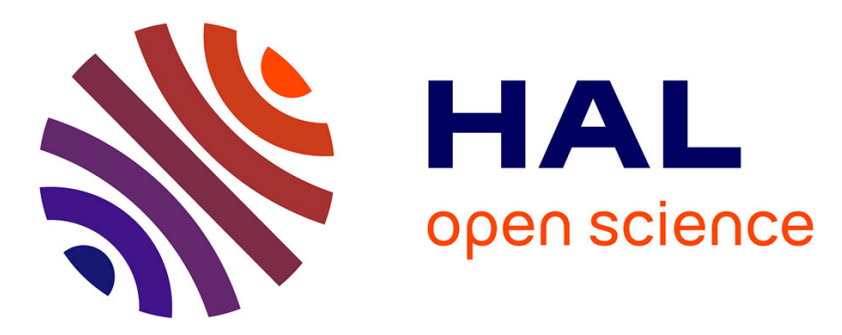

\title{
Increased risk of type 2 diabetes in antidepressant users: evidence from a 6-year longitudinal study in the E3N cohort
}

Marine Azevedo da Silva, Agnès Fournier, Marie Christine Boutron-Ruault, Beverley J. Balkau, Fabrice Bonnet, H. Nabi, Guy Fagherazzi

\section{To cite this version:}

Marine Azevedo da Silva, Agnès Fournier, Marie Christine Boutron-Ruault, Beverley J. Balkau, Fabrice Bonnet, et al.. Increased risk of type 2 diabetes in antidepressant users: evidence from a 6-year longitudinal study in the E3N cohort. Diabetic Medicine, 2020, 37 (11), pp.1866-1873. 10.1111/dme.14345 . hal-03032299

\section{HAL Id: hal-03032299 https://hal.science/hal-03032299}

Submitted on 25 Jan 2021

HAL is a multi-disciplinary open access archive for the deposit and dissemination of scientific research documents, whether they are published or not. The documents may come from teaching and research institutions in France or abroad, or from public or private research centers.
L'archive ouverte pluridisciplinaire HAL, est destinée au dépôt et à la diffusion de documents scientifiques de niveau recherche, publiés ou non, émanant des établissements d'enseignement et de recherche français ou étrangers, des laboratoires publics ou privés. 
DR BEVERLEY BALKAU (Orcid ID : 0000-0003-2021-413X)

DR GUY FAGHERAZZI (Orcid ID : 0000-0001-5033-5966)

Article type : Research Article

Title: Diabetic Medicine

Created by: Maria Davie

Email proofs to: guy.fagherazzi@lih.lu

Article no.: DME-2020-00064

Accepted date: 05 June 2020

Article type: Research Article

Short title/Authors running head: • M. Azevedo Da Silva et al.

\section{Increased risk of type 2 diabetes in antidepressant users:}

\section{evidence from a 6-year longitudinal study in the E3N cohort}

M. Azevedo Da Silva ${ }^{1,2}$, A. Fournier ${ }^{2,3,4}$, M.-C. Boutron-Ruault ${ }^{2-4}$, B. Balkau ${ }^{2,3,5}$, F. Bonnet ${ }^{2-6}$, H. Nabi $^{2,7-}$ ${ }^{9}$ and G. Fagherazzi ${ }^{2-4,10}$

${ }^{1}$ Institute for Health and Social Policy, McGill University, Montreal, Quebec, Canada, ${ }^{2}$ INSERM U1018, Centre for Research in Epidemiology and Population Health, Villejuif, France, ${ }^{3}$ University Paris-Saclay, University Paris-Sud, Villejuif, France, ${ }^{4}$ Gustave Roussy Institute, Villejuif, France, ${ }^{5}$ University Versailles-St Quentin, University Paris-Sud, Paris, France, ${ }^{6} \mathrm{CHU}$ Rennes, Rennes, France, ${ }^{7}$ Département

This article has been accepted for publication and undergone full peer review but has not been through the copyediting, typesetting, pagination and proofreading process, which may lead to differences between this version and the Version of Record. Please cite this article as doi: 10.1111/DME.14345

This article is protected by copyright. All rights reserved 
de Médecine Sociale et Préventive, Faculté de Médecine, ${ }^{8}$ Axe Oncologie, Centre de Recherche du CHU de Québec and ${ }^{9}$ Centre de Recherche sur le Cancer, Université Laval, Québec, QC, Canada, and ${ }^{10}$ Luxembourg Institute of Health, Department of Population Health, Strassen, Luxembourg

\section{Correspondence to:}

Guy Fagherazzi. E-mail: guy.fagherazzi@lih.lu

\section{What's new?}

- Although meta-analyses have concluded that the use of antidepressants is associated with an increased risk of type 2 diabetes, this association remains debated. Two longitudinal studies found no association between the use of antidepressants and change in glucose levels over time.

- This prospective study found that current antidepressant users were at a higher risk of developing type 2 diabetes during follow-up than non-users, regardless of the type of antidepressant and even after adjusting for symptoms of severe depression.

- The negative effects of using antidepressants on the risk of type 2 diabetes might have important clinical implications for the management of people in need of chronic antidepressant medications.

\section{Abstract}

Aim

To examine the association between antidepressant medication use and the risk of type 2 diabetes.

Methods Data were obtained from the E3N study (Étude Épidémiologique de Femmes de la Mutuelle Générale de l'Éducation Nationale), a French cohort study initiated in 1990, with questionnaire-based follow-up every 2 or 3 years. Exposure to antidepressants was obtained from drug reimbursement files 
available from 2004 onwards, and individually matched with questionnaire data. Cases of type 2 diabetes were identified from drug reimbursements. Cox proportional-hazard regression models were used, with drug exposure considered as a time-varying parameter.

Results Of the 63999 women who were free of drug-treated type 2 diabetes at baseline in 2005, 1124 developed type 2 diabetes over the 6-year follow-up. Current use of antidepressants was associated with an increased risk of type 2 diabetes [hazard ratio 1.34 (95\% CI 1.12, 1.61)] compared to non-users. When the different types of antidepressants were considered, women who currently used selective serotonin reuptake inhibitors, imipramine-type, 'other' or 'mixed' antidepressants had a 1.25 -fold (95\% CI 0.99 , 1.57), 1.66-fold (95\% CI 1.12, 2.46), 1.35-fold (95\% CI 1.00, 1.84) and 1.82-fold (95\% CI 0.85, 3.86) increase in risk of type 2 diabetes compared to non-users, respectively.

Conclusion Our study suggests a positive association between antidepressant use and the risk of type 2 diabetes among women. If this association is confirmed, screening and surveillance of glucose levels should be considered in the context of antidepressant therapy. Further studies assessing the underlying mechanisms of this association are needed.

(ClinicalTrials.gov identifier: NCT03285230).

\section{Introduction}

Preventing type 2 diabetes is a public health priority worldwide, as this disease is associated with major complications such as retinopathy, neuropathy, nephropathy, cardiovascular disease, depression and poor quality of life [1]. In addition, significant healthcare costs are associated with its management [2]. Prominent risk factors for type 2 diabetes include a family history of diabetes, eating behaviours, overweight, high waist circumference, physical inactivity, advanced age, high blood pressure, ethnicity and education level [3].

This article is protected by copyright. All rights reserved 
The association between the use of antidepressants and the risk of developing type 2 diabetes in the general population has been controversial. Findings from secondary analyses of the Diabetes Prevention Programme randomized controlled trial supported a positive association between their use and the risk of developing type 2 diabetes [4]. Subsequent observational studies yielded conflicting results. Some of these reported antidepressant users to be at greater risk of developing type 2 diabetes compared to nonusers [5,6], while others did not find an association [7,8].

Three meta-analyses [9-11] and a systematic review [12] concluded that the use of antidepressants was associated with an increased risk of type 2 diabetes. However, two longitudinal studies found no association between the use of antidepressants and change in glucose levels over time $[13,14]$. The association between antidepressant use and type 2 diabetes therefore remains unclear and requires additional studies that can take into account the evolution over time of the use of different classes of antidepressants.

We used longitudinal data from the French E3N cohort study (Étude Épidémiologique de Femmes de la Mutuelle Générale de l'Éducation Nationale) to prospectively examine the association between the use of antidepressants and the risk of developing type 2 diabetes; information on exposure to antidepressants was updated during follow-up, and data on type of antidepressant used were available.

\section{Methods}

\section{Study population}

The French E3N prospective cohort study was established in 1990 with the initial objective being to study risk factors for cancers in women [15]. This goal has since been expanded to include other chronic diseases. The E3N study is the French component of the European Prospective Investigation into Cancer and Nutrition (EPIC) and is part of EPIC-InterAct, a case-cohort study on type 2 diabetes nested within EPIC [16]. The E3N cohort included 98995 women, aged 40-65 years, living in France, who were insured by a health insurance plan that mostly covers teachers. Data are obtained from mailed 
questionnaires sent every 2-3 years. The health insurance plan has provided all outpatient reimbursements for health expenditure since 1 January 2004. The follow-up questionnaire response rate has remained stable at approximately $80 \%$, and the total loss to follow-up since 1990 has been $3 \%$.

The present analyses included 63999 women who responded to the questionnaire in 2005, were free of drug-treated type 2 diabetes in 2005 and were still affiliated with the health insurance plan (Fig. 1). This questionnaire in 2005 was the baseline for the present study, as it was the first questionnaire available after the health expenditure reimbursement database was initiated in 2004, and the first time that information on depressive symptoms was available. The latest available data were from 1 January 2011, representing the end of follow-up.

\section{Measurements}

\section{Antidepressant use}

From the drug reimbursement files, antidepressant drugs were identifiable through the Anatomical Therapeutic Chemical (ATC) classification code N06A ('antidepressants'). The different classes of antidepressants were established using ATC codes N06AA for imipramine type, N06AB for selective serotonin reuptake inhibitors, N06AF and N06AG for monoamine oxidase inhibitors and N06AX for other antidepressants (e.g. serotonin and noradrenaline reuptake inhibitors, tetracyclics, and selective serotonin reuptake enhancers). The drug reimbursement files also included the French identifier code for presentations (CIP) and the date of purchase of the drug.

All antidepressant reimbursements during follow-up were extracted. To identify episodes of use versus non-use of antidepressants and assuming that the date of purchase corresponded with the 'start date' of use, we estimated the 'end date' using a three-step approach.

We first obtained the dose (mg) per container (packet of tablets, packet of ampoules, bottle) from the CIP for each antidepressant. In the second step, usual daily doses for adults of the different antidepressants were estimated based on Thesorimed ${ }^{\circledR}$ (https://theso.prod-un.thesorimed.org/index), a database of drugs 
marketed in France, developed and made available by the French Health Insurance System. For each drug, the period of use in days was calculated by dividing the dose per container by the usual daily dosages. Finally, in the third step, with the recommended number of treatment days per container, it was possible to calculate an estimated 'end date' of use per purchase. If fewer than 90 days separated the end date of a purchase and the date of the next purchase, the period of use was considered as nondiscontinued. Otherwise, the time between the end date of the first purchase and the start date of the next was considered a period of non-use.

Throughout the follow-up, a three-category variable indicating the use of antidepressants was created: 1, none; 2, past; and 3, current. A six-category variable was also created: 1, participants not using antidepressants; 2, past use of any antidepressant; 3, current use of imipramine-type antidepressants only; 4, current use of 'selective serotonin reuptake inhibitors' only; 5, current use of 'other' class of antidepressants; and 6, current use of a combination of antidepressants ('mixed' group). For this work, the category 'current use of monoamine oxidase inhibitors only' was not included as there were only few monoamine oxidase inhibitor reimbursements in the E3N cohort during follow-up. This can be explained by the low prescription rate for this drug, given its recognized adverse side effects.

\section{Ascertainment of type 2 diabetes cases}

Type 2 diabetes cases were identified through the drug reimbursement database; women reimbursed at least twice for glucose-lowering medications within a sliding period of 1 year were classified as having type 2 diabetes, with the date of diagnosis defined as the date of first reimbursement [17].

\section{Statistical analysis}

Differences in baseline characteristics of participants by antidepressant medication use over the period 2005-2011 were assessed using chi-squared tests or analysis of variance, as appropriate.

To examine relationships between antidepressant use and incident type 2 diabetes, we used Cox proportional hazard regression models with age as the time scale [18], treating antidepressant use as a 
time-varying exposure to allow for participants starting and stopping and also changing treatments during follow-up. Hazard ratios (HRs) and 95\% CIs for incident type 2 diabetes were computed from 2005 to the date of incident type 2 diabetes, death, or end of follow-up in 2011, whichever occurred first. The proportional hazards assumptions were confirmed by Schoenfeld tests [19].

Statistical analyses were controlled for potentially confounding variables, selected based on the literature and formal bivariate tests (considered relevant at $P \leq 0.1$ ). In model 1 , HRs were adjusted for sociodemographic factors that included marital status (single, married or living with a partner, widowed, divorced or separated), education level $(<12,12-15, \geq 15$ years) and occupational status (working, nonworking). In model 2, HRs were additionally adjusted for smoking (non-smoker, former smoker, smoker), alcohol consumption (none, moderate, heavy), physical activity (quartiles of MET-h/week, where MET is metabolic equivalent of task), BMI $\left(\mathrm{kg} / \mathrm{m}^{2}\right)$, hip circumference $(\mathrm{cm})$ and waist circumference $(\mathrm{cm})$. In model 3, HRs were additionally adjusted for severe depressive symptoms [identified using the Centre for Epidemiological Studies Depression Scale (CES-D) [20], with a score threshold of $\geq 23$ chosen to define severe depressive symptoms [21]], family history of diabetes (no, yes), hypertension (no, yes), the number of ambulatory medical visits in the past 12 months (grouped by tertile of number of ambulatory medical visits). In the final model 4 , HRs were additionally adjusted for baseline medication use other than antidepressants and included menopausal hormone therapy use (none, past, current), antipsychotic medication use (ATC N05A; none, past, current), anxiolytic medication use (ATC N05B; none, past, current), hypnotic medication use or sedative medication use (ATC N05C; none, past, current). In these four models, confounding variables were ascertained at baseline (date of response to the 2005 questionnaire). Missing data on confounding variables were replaced according to the three hierarchical steps: 1) replacement by the data from the previous self-administered questionnaire where the variable concerned was measured; 2) replacement by mode (for qualitative variables) or median (for quantitative variables) in the case of a missing data count of $\leq 5 \%$; and 3) creation of a 'missing' category.

Analyses used STATA software (version 16; Stata Corp, College Station, TX, USA).

This article is protected by copyright. All rights reserved 


\section{Ethics}

All participants signed an informed consent form at study entry, and the study protocol was approved by the French National Commission for Computed Data and Individual Freedom. E3N was approved by this French Commission for Data Protection and Privacy.

\section{Results}

The baseline characteristics of the 63999 women, mean (SD) age 64 (6) years, are presented in Table 1, according to the use of antidepressants over the follow-up period. Based on data from reimbursement files, a total of 16779 (26\%) women used antidepressants at least once during follow-up. Antidepressant users were slightly older, more often widowed, divorced or separated, had a lower level of education, were more likely to be smokers and to not drink alcohol, and had a lower physical activity level, a higher BMI, and higher waist and hip circumferences when compared to non-users. They were also more likely to have severe symptoms of depression, hypertension, were more often on menopausal hormone treatment and more frequently used other psychotropic drugs. Finally, they had a higher number of visits in ambulatory medicine.

The 63999 women had a median follow-up of 6.4 years, which contributed 377140 person-years, and 1124 women were diagnosed with type 2 diabetes (incidence rate 2.98 per 1000 person-years). When antidepressant medication use was considered as a six-category variable, only 63996 women were included because of the exclusion of three women using monoamine oxidase inhibitors.

Table 2 shows the association of antidepressant medication use with the risk of incident type 2 diabetes. In model 1 adjusted for sociodemographic characteristics, current antidepressant users were at higher risk of developing type 2 diabetes [HR 1.82 (95\% CI 1.54, 2.14)] than non-users. After further adjusting for all covariates (model 4), the strength of the association was reduced [hazard ratio 1.34 (95\% CI 1.12, 
1.61)] in current antidepressant users. There were no differences in the risk of incident type 2 diabetes among past-users [HR 0.97 (95\% CI 0.79, 1.18)] compared to non-users.

When the type of antidepressant used was considered, after adjusting for all confounding factors, model 4, women using imipramine-type antidepressants [HR 1.66 (95\% CI 1.12, 2.46)), selective serotonin reuptake inhibitors [HR 1.25 (95\% CI 0.99, 1.57)], other antidepressants [HR 1.35 (95\% CI 1.00, 1.84)] or mixed antidepressants [HR 1.82 (95\% CI 0.85, 3.86)] had an increased risk of developing type 2 diabetes compared to non-users. There was no heterogeneity among these four pharmacological classes of current antidepressant $(P$ homogeneity $=0.516)$, after adjusting for all covariates.

In a sensitivity analysis in which the updated information on BMI from the 2008 questionnaire was also used in each model (i.e. BMI was introduced as a time-varying covariate rather than being fixed at baseline), our risk estimates were only marginally modified (data not shown).

\section{Discussion}

This study, conducted in nearly 64000 women from the E3N cohort, sought to examine the association between antidepressant use and the risk of developing type 2 diabetes, over 6 years of follow-up. After adjusting for a wide range of potential confounding factors, including severe depressive symptoms, current antidepressant users were still at a higher risk of developing type 2 diabetes during follow-up, compared to non-users. When the type of antidepressant was considered, there was no significant difference between the hazard ratios according to the type of antidepressant, after controlling for confounders.

Our results are consistent with the majority of registry-based observational studies [5,6,22-24] and three meta-analyses [9-11] that found an association between antidepressant medication use and the risk of type 2 diabetes. However, these meta-analyses pointed out the large heterogeneity among studies as well as a lack of robustness in the results, particularly when certain studies were excluded from the models in sensitivity analyses. In a Finnish occupational case-control study nested in a cohort [6], antidepressant 
use was associated with an increased risk of type 2 diabetes in participants without evidence of severe depression [odds ratio 1.68 (95\% CI 1.27, 2.21)], as well as in participants with severe depression [odds ratio 2.76 (95\% CI 1.93, 3.94)]. In a US study [5] pooling data from the Health Professional Study (19902006), the Nurses' Health Study (1996-2008) and the Nurses' Health Study II (1993-2005), the authors found an association between the use of antidepressants and the risk of type 2 diabetes [HR 1.17 (95\% CI $1.09,1.25)]$. In a case-control study nested in the UK General Practice Research cohort of people with depression [22], the recent long-term (>24 months) use of antidepressants at moderate to high daily doses was associated with an increased risk of type 2 diabetes [incidence rate ratio 1.84 (95\% CI 1.35, 2.52)] compared to non-users in the past 2 years. Finally, in the Women's Health Initiative including postmenopausal women [23], an increased risk of type 2 diabetes was observed in users of antidepressants [HR $1.18(95 \%$ CI 1.10, 1.28)] compared to non-users. The three meta-analyses conducted in 2013 [9-11] and the systematic review [12] concluded that the use of antidepressants was associated with an increased risk of type 2 diabetes.

The mechanisms underlying the association between the use of antidepressants and type 2 diabetes remain to be explored. The literature suggests that weight gain induced by psychotropic drugs is usually preceded by an increased appetite, especially for foods high in fat and sugars [25]. An increased dietary intake was also highlighted in non-depressed individuals treated with imipramine antidepressants [26]. Therefore, it is possible that the functioning of the central nervous system regulating appetite and food intake is altered by antidepressant use. Indeed, fluoxetine (selective serotonin reuptake inhibitor) has been shown to activate a decrease in leptin concentration in rodents [27]. Leptin is a signalling protein participating in the regulation of the hypothalamic satiety centre and fat reserves of the body [28] and a low plasma leptin concentration stimulates food intake and vice versa [29]. Moreover, hyperglycaemia was associated with the use of antidepressants with a high affinity for the histamine 1 receptor (H1-R; mainly imipramine-type antidepressants, such as amitriptyline, imipramine, trimipramine, clomipramine, and some other types, such as mirtazapine), a receptor associated with weight gain and metabolic abnormalities [30]. However,

This article is protected by copyright. All rights reserved 
whether adjusting our models for BMI measured at baseline or BMI updated during follow-up (so as to take into account variations in weight during follow-up), we consistently found higher risks of developing type 2 diabetes in current antidepressant users.

Strengths of the present study include the fact that it comprised a large number of women with a 6-year follow-up, taking into account different pharmacological classes of antidepressants and a wide range of potential confounders. In contrast to a number of previous studies, we were able to account for changes in antidepressant use during follow-up. Since antidepressant reimbursement data have been prospectively recorded prior to the onset of type 2 diabetes, memory bias, if it exists, is likely to be non-differential. Finally, it was possible to take into account a wide range of potential confounding factors, in particular, the existence of severe depression symptoms; thus, risk estimates should relate to the use of antidepressants rather than severe depression itself. Since people treated with antidepressants are more likely to use the healthcare system than untreated people, and therefore may be more likely to be diagnosed with another health problem such as diabetes, our analyses were adjusted for the frequency of ambulatory medical visits in the year preceding baseline, in order to limit detection bias.

Nevertheless, the results of this study should be interpreted in the light of some limitations. First, the majority of potential confounding variables were self-reported and may therefore be subject to reporting bias. Second, some biases may persist in the comparisons between antidepressant types if the choice of a particular antidepressant class was influenced by risk factors for type 2 diabetes, however, a wide range of potential confounders were taken into account in the analysis to reduce differences between groups. Third, residual confounding may still be present due to variables that have not been collected or not recorded with enough detail to completely remove confounding from the analysis. Although analyses were adjusted for severe symptoms of depression, because the CES-D scale is not a diagnostic tool, it was not possible to capture all the relevant components of depression. Fourth, misclassification of antidepressant use may have occurred because some women may not have taken all or even part of their prescription. These misclassification errors may have underestimated the associations reported in the 
study. Fifth, cases of type 2 diabetes which were not pharmacologically treated were classified as noncases. This may have lowered the magnitude of the association between antidepressant use and type 2 diabetes. However, we think this would have an inconsequential influence on the results [31]. Finally, as the study population included only women, mostly employed in education, the results cannot be directly extrapolated to men or to the general population.

In conclusion, findings from this cohort study in French women suggest that the use of antidepressants is associated with the risk of developing type 2 diabetes. The negative effects of using antidepressants on the risk of type 2 diabetes might have important clinical implications for the management of people in need of chronic antidepressant medications. Nonetheless, the nature of the mechanisms underlying this association remains unclear and requires further study.

\section{Funding sources}

M.A.D.S. was the recipient of a doctoral fellowship from the Ministère de l'Enseignement Supérieur et de la Recherche, Paris, France. The E3N cohort is being conducted with the financial support of the Mutuelle Générale de l'Education Nationale, the European Community, the French League against Cancer, Gustave Roussy, and the French Institute of Health and Medical Research. The validation of potential type 2 diabetes cases was supported by the European Union (Integrated Project LSHM-CT-2006-037197 in the 6th European Community Framework Programme). G.F. was supported by a grant for the E4N study from the Agence Nationale de Recherche (ANR-10-COHO-0006 grant), and an IDEX grant (NUTRIPERSO project) from Paris Saclay University.

\section{Competing interests}

None declared.

This article is protected by copyright. All rights reserved 


\section{Acknowledgements}

The authors are indebted to all participants for their continued participation and to all members of the E3N study group.

\section{Availability of data and materials}

The datasets generated and/or analysed for the present study are not publicly available due to ethical reasons, permission by the participants to use their data, according to the signed informed consent, and from the MGEN, their insurance company. Data use is restricted to the team in charge of the cohort. However, data use can be extended to collaborators with a specific research agreement in collaboration with the corresponding author, on reasonable request.

\section{References}

1. Fosse-Edorh S, Mandereau-Bruno L, Regnault N. The burden of diabetes-related complications in France in 2013. Summary and perspectives. Bull Epidémiol Hebd 2015; 619625.

2. da Rocha Fernandes J, Ogurtsova K, Linnenkamp U, Guariguata L, Seuring T, Zhang P et al. IDF Diabetes Atlas estimates of 2014 global health expenditures on diabetes. Diabetes Res Clin Pract 2016; 117: 48-54.

3. WHO. Global report on diabetes. [cited 2018 Apr 6]. Available at http://www.who.int/diabetes/global-report/en/. Last accessed 7 January 2020. 
4. Rubin RR, Ma Y, Marrero DG, Peyrot M, Barrett-Connor EL, Kahn SE et al. Elevated depression symptoms, antidepressant medicine use, and risk of developing diabetes during the diabetes prevention program. Diabetes Care 2008; 31: 420-426.

5. Pan A, Sun Q, Okereke OI, Rexrode KM, Rubin RR, Lucas M et al. Use of antidepressant medication and risk of type 2 diabetes: results from three cohorts of US adults. Diabetologia 2012; 55: 63-72.

6. Kivimäki M, Hamer M, Batty GD, Geddes JR, Tabak AG, Pentti J et al. Antidepressant medication use, weight gain, and risk of type 2 diabetes: a population-based study. Diabetes Care 2010; 33: 2611-2616.

7. Bhattacharya R, Ajmera M, Bhattacharjee S, Sambamoorthi U. Use of antidepressants and statins and short-term risk of new-onset diabetes among high risk adults. Diabetes Res Clin Pract 2014; 105: 251-260.

8. Chang KJ, Hong CH, Lee Y, Lee KS, Roh HW, Back JH et al. Effect of Psychotropic Drugs on Development of Diabetes Mellitus in Patients With Alzheimer's Disease. Medicine (Baltimore) 2015; 94: e919.

9. Bhattacharjee S, Bhattacharya R, Kelley GA, Sambamoorthi U. Antidepressant use and newonset diabetes: a systematic review and meta-analysis. Diabetes Metab Res Rev 2013; 29: 273284.

10. Yoon JM, Cho E-G, Lee H-K, Park SM. Antidepressant use and diabetes mellitus risk: a meta-analysis. Korean J Fam Med 2013; 34: 228-240.

This article is protected by copyright. All rights reserved 
11. Salvi V, Grua I, Cerveri G, Mencacci C, Barone-Adesi F. The risk of new-onset diabetes in antidepressant users - A systematic review and meta-analysis. PloS One 2017; 12: e0182088.

12. Barnard K, Peveler RC, Holt RIG. Antidepressant medication as a risk factor for type 2 diabetes and impaired glucose regulation: systematic review. Diabetes Care 2013; 36: 33373345.

13. Kivimäki M, Batty GD, Jokela M, Ebmeier KP, Vahtera J, Virtanen M et al. Antidepressant medication use and risk of hyperglycemia and diabetes mellitus: a noncausal association? Biol Psychiatry 2011; 70: 978-984.

14. Azevedo Da Silva M, Dugravot A, Balkau B, Roussel R, Fumeron F, Elbaz A et al. Antidepressant medication use and trajectories of fasting plasma glucose, glycated haemoglobin, $\beta$-cell function and insulin sensitivity: a 9-year longitudinal study of the D.E.S.I.R. cohort. Int $J$ Epidemiol 2015; 44: 1927-1940.

15. Clavel-Chapelon F, E3N Study Group. Cohort Profile: The French E3N Cohort Study. Int J Epidemiol 2015; 44: 801-809.

16. Kengne AP, Beulens JWJ, Peelen LM, Moons KGM, van der Schouw YT, Schulze MB et al. Non-invasive risk scores for prediction of type 2 diabetes (EPIC-InterAct): a validation of existing models. Lancet Diabetes Endocrinol 2014; 2: 19-29.

17. Mancini FR, Dow C, Affret A, Rajaobelina K, Dartois L, Balkau B et al. Micronutrient dietary patterns associated with type 2 diabetes mellitus among women of the E3N-EPIC (Etude Epidémiologique auprès de femmes de l'Education Nationale) cohort study. J Diabetes 2018; 10: $665-674$.

This article is protected by copyright. All rights reserved 
18. Thiébaut ACM, Bénichou J. Choice of time-scale in Cox's model analysis of epidemiologic cohort data: a simulation study. Stat Med 2004; 23: 3803-3820.

19. Schoenfeld D. Partial residuals for the proportional hazards regression model. Biometrika 1982; 69: 239-241.

20. Radloff LS. The CES-D Scale: A self-report depression scale for research in the general population. Appl Psychol Meas 1977; 1: 385-401.

21. Fuhrer R, Rouillon F. La version française de l'échelle CES-D (Center for Epidemiologic Studies-Depression Scale). Description et traduction de l'échelle d'autoévaluation. [The French version of the CES-D (Center for Epidemiologic Studies-Depression Scale).]. Psychiatr Psychobiol 1989; 4: 163-166.

22. Andersohn F, Schade R, Suissa S, Garbe E. Long-term use of antidepressants for depressive disorders and the risk of diabetes mellitus. Am J Psychiatry 2009; 166: 591-598.

23. Ma Y, Balasubramanian R, Pagoto SL, Schneider KL, Culver AL, Olendzki B et al. Elevated depressive symptoms, antidepressant use, and diabetes in a large multiethnic national sample of postmenopausal women. Diabetes Care 2011; 34: 2390-2392.

24. Khoza S, Barner JC, Bohman TM, Rascati K, Lawson K, Wilson JP. Use of antidepressant agents and the risk of type 2 diabetes. Eur J Clin Pharmacol 2012; 68: 1295-1302.

25. Kazes M, Danion JM, Grangé D, Pradignac A, Simon C, Burrus-Mehl F et al. Eating behaviour and depression before and after antidepressant treatment: a prospective, naturalistic study. J Affect Disord 1994; 30: 193-207.

This article is protected by copyright. All rights reserved 
26. Garland EJ, Remick RA, Zis AP. Weight gain with antidepressants and lithium. J Clin Psychopharmacol 1988; 8: 323-330.

27. Dryden S, Brown M, King P, Williams G. Decreased plasma leptin levels in lean and obese Zucker rats after treatment with the serotonin reuptake inhibitor fluoxetine. Horm Metab Res 1999; 31: 363-366.

28. Ahima RS. Revisiting leptin's role in obesity and weight loss. J Clin Invest 2008; 118: 23802383.

29. Friedman JM, Halaas JL. Leptin and the regulation of body weight in mammals. Nature 1998; 395: 763-770.

30. Salvi V, Barone-Adesi F, D’Ambrosio V, Albert U, Maina G. High H1-affinity antidepressants and risk of metabolic syndrome in bipolar disorder. Psychopharmacology (Berl) 2016; 233: 49-56.

31. Fagherazzi G, El Fatouhi D, Fournier A, Gusto G, Mancini FR, Balkau B et al. Associations Between Migraine and Type 2 Diabetes in Women. JAMA Neurol 2019; 76: 257-263.

FIGURE 1 Study flow diagram.

This article is protected by copyright. All rights reserved 
Table 1 Baseline characteristics of women (2005) by antidepressant use over follow-up (2005-

2011) in the E3N study

\begin{tabular}{|c|c|c|c|c|c|c|c|}
\hline \multirow{4}{*}{$\begin{array}{l}\text { Characteristic at baseline (2005) } \\
\text { Mean (SD) age, years }\end{array}$} & \multirow{3}{*}{\multicolumn{2}{|c|}{$\begin{array}{c}\text { Total } \\
N=63999\end{array}$}} & \multicolumn{5}{|c|}{ Antidepressant use over follow-up (2005-2011) } \\
\hline & & & \multirow{2}{*}{\multicolumn{2}{|c|}{$\begin{array}{c}\text { None } \\
N=47220\end{array}$}} & \multicolumn{2}{|c|}{ At least once } & \multirow{2}{*}{$P$} \\
\hline & & & & & $N=$ & 6779 & \\
\hline & 64.3 & $(6.3)$ & 64.2 & $(6.2)$ & 64.6 & $(6.6)$ & $<0.001$ \\
\hline Marital status, $n(\%)$ & & & & & & & $<0.001$ \\
\hline Single & 3965 & (6) & 2958 & (6) & 1007 & (6) & \\
\hline Married or living with a partner & 45721 & $(71)$ & 34188 & (73) & 11533 & $(69)$ & \\
\hline widowed & 6706 & (11) & 4827 & (10) & 1879 & (11) & \\
\hline Divorced or separated & 7607 & $(12)$ & 5247 & (11) & 2360 & (14) & \\
\hline Education level, $n(\%)$ & & & & & & & $<0.001$ \\
\hline$<12$ years & 6129 & $(10)$ & 4381 & (9) & 1748 & $(10)$ & \\
\hline $12-14$ years & 34726 & (54) & 25513 & (54) & 9213 & $(55)$ & \\
\hline$\geq 15$ years & 23144 & $(36)$ & 17326 & (37) & 5818 & $(35)$ & \\
\hline Occupational status, $n(\%)$ & & & & & & & 0.070 \\
\hline Working & 50823 & (79) & 37580 & $(80)$ & 13243 & (79) & \\
\hline Non-working & 13176 & $(21)$ & 9640 & $(20)$ & 3536 & $(21)$ & \\
\hline Smoking status, $n(\%)$ & & & & & & & $<0.001$ \\
\hline Non-smoker & 34054 & $(53)$ & 25408 & $(54)$ & 8646 & $(51)$ & \\
\hline Former smoker & 25540 & $(40)$ & 18852 & $(40)$ & 6688 & $(40)$ & \\
\hline Smoker & 4405 & (7) & 2960 & (6) & 1445 & $(9)$ & \\
\hline Alcohol consumption, $n(\%)$ & & & & & & & $<0.001$ \\
\hline None ( 0 g per day) & 8851 & (14) & 6112 & (13) & 2739 & (16) & \\
\hline Moderate (1-20 g per day) & 41446 & $(65)$ & 31005 & $(66)$ & 10441 & $(62)$ & \\
\hline Heavy (>20 g per day) & 13702 & (21) & 10103 & (21) & 3599 & $(22)$ & \\
\hline
\end{tabular}

This article is protected by copyright. All rights reserved 
Physical activity, $n(\%)$

$<0.001$

Quartile 1 (0-32.90 MET-h/week)

$9721 \quad(21)$

$4356 \quad(26)$

Quartile 2 (32.91-55.50 MET-h/week)

$14853 \quad(23) \quad 10964 \quad(23)$

$3889 \quad(23)$

Quartile 3 (55.51-86.50 MET-h/week)

$15342 \quad(24) \quad 11596 \quad(25)$

$3746 \quad(22)$

Quartile 4 ( $\geq 86.51$ MET-h/week)

$15673 \quad(25)$

$12064 \quad(25)$

$3609 \quad(22)$

Missing, $n(\%)$

$4054 \quad(6)$

$2875 \quad(6)$

$1179 \quad(7)$

Mean (SD) BMI, $\mathrm{kg} / \mathrm{m}^{2}$

$23.7 \quad(3.7) \quad 23.6 \quad(3.6)$

$23.8 \quad(3.9)$

$<0.001$

Mean (SD) aist circumference, $\mathrm{cm}$

$80.2 \quad(9.8)$

$79.9 \quad(9.6)$

$81.0 \quad(10.2)$

$<0.001$

Mean (SD) hip circumference, $\mathrm{cm}$

$98.4 \quad(8.5)$

$99.0 \quad(9.0)$

$<0.001$

Severe depressive symptoms (CES-D), $n(\%)$

$98.5 \quad(8.6)$

$<0.001$

No $(<23)$

$48043 \quad(75)$

$37493 \quad(79)$

$10550 \quad(63)$

Yes $(\geq 23)$

$6435 \quad(10)$

$3100 \quad(7)$

$3335 \quad(20)$

$9521 \quad(15)$

$6627 \quad(14)$

$2894 \quad(17)$

Family history of diabetes, $n(\%)$

0.113

No

$55633 \quad(87)$

$40988 \quad(87)$

$14645 \quad(87)$

$8366 \quad(13)$

$6232 \quad(13)$

$2134 \quad(13)$

Hypertension, $n(\%)$

$\begin{aligned} 54726 & (85) & 40783 & (86) & 13943 & (83) \\ 9273 & (15) & 6437 & (14) & 2836 & (17)\end{aligned}$

No

Yes

$9273-(15)$

Tertile of number of visits in ambulatory

medicine in the past 12 months, $n(\%)$

Tertile $1(0-5)$

$18586 \quad(29)$

$15845 \quad$ (34)

$2741 \quad(16)$

Tertile $2(6-11)$

$27095 \quad(42)$

$20515 \quad(43)$

$6580 \quad(39)$

Tertile $3(>11)$

$18318 \quad(29)$

$10860 \quad(23)$

$7458 \quad(45)$

Menopausal hormone therapy use, $n(\%)$

None

$19869 \quad(31)$

$15277 \quad(32)$

$<0.001$

Past

$29902 \quad$ (47)

$21709 \quad$ (46)

$4592 \quad(27)$

Current

$14228 \quad(22)$

$10234 \quad$ (22)

$8193 \quad$ (49)

$3994 \quad$ (24) 
Antipsychotic medication use, $n(\%)$

$<0.001$

\begin{tabular}{|c|c|c|c|c|c|}
\hline None & 60515 & (94) & 45502 & (96) & 15013 \\
\hline Past & 1104 & (2) & 659 & (2) & 445 \\
\hline Current & 2380 & (4) & 1059 & (2) & 1321 \\
\hline
\end{tabular}

Anxiolytic medication use, $n(\%)$

46356

$4015 \quad(6)$

13628

(21)

$6669 \quad(14)$

52533

$2438 \quad(4)$

$9028 \quad(14)$

$38079 \quad(81)$
$<0.001$

$8277 \quad$ (49)

1543 (9)

$6959 \quad(42)$

$<0.001$

$11597 \quad(69)$

$940 \quad(6)$

$4242 \quad(25)$
None

Past

Current

Hypnotic or sedative medication, $n(\%)$

None

Past

Current
CES-D, Centre for Epidemiological Studies Depression Scale; MET, metabolic equivalent of task. 
Table 2 Association between antidepressant medication use and the risk of type 2 diabetes onset in the E3N study

\begin{tabular}{|c|c|c|c|c|c|c|c|c|c|c|c|c|c|c|}
\hline \multirow{2}{*}{ 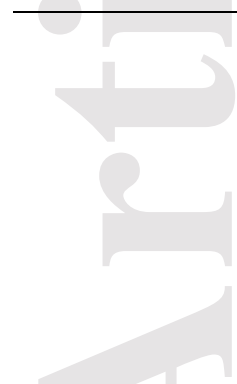 } & & Incidence & & Model 1* & & & Model 2 & & & Model 3 & & & Model 4 & \\
\hline & cases/N & $\begin{array}{l}1000 \\
\text { person- } \\
\text { years }\end{array}$ & HR & $95 \% \mathrm{CI}$ & $P$ & HR & $95 \% \mathrm{CI}$ & $P$ & HR & $95 \% \mathrm{CI}$ & $P$ & HR & $95 \%$ CI & $P$ \\
\hline
\end{tabular}

\begin{tabular}{|c|c|c|c|c|c|c|c|c|c|c|c|c|c|c|}
\hline \multicolumn{15}{|l|}{ Antidepressant use } \\
\hline None & $834 / 304415$ & 2.73 & \multicolumn{2}{|c|}{ Reference } & \multicolumn{4}{|c|}{ Reference } & \multicolumn{2}{|c|}{ Reference } & \multicolumn{4}{|c|}{ Reference } \\
\hline Past & $120 / 39791$ & 3.02 & 1.08 & $(0.89,1.31)$ & 0.440 & 1.04 & $(0.86,1.26)$ & 0.688 & 0.99 & $(0.81,1.20)$ & 0.894 & 0.97 & $(0.79,1.18)$ & 0.760 \\
\hline Current & $170 / 32934$ & 5.16 & 1.82 & $(1.54,2.14)$ & $<0.001$ & 1.48 & $(1.25,1.75)$ & $<0.001$ & 1.38 & $(1.16,1.64)$ & $<0.001$ & 1.34 & $(1.12,1.61)$ & 0.002 \\
\hline Antidepressant use & & & & & $0.543^{\pi}$ & & & $0.458^{\text {n }}$ & & & $0.514^{\pi}$ & & & $0.516^{\text {वी }}$ \\
\hline None & $834 / 304415$ & 2.74 & \multicolumn{2}{|c|}{ Reference } & \multicolumn{4}{|c|}{ Reference } & \multicolumn{2}{|c|}{ Reference } & \multicolumn{4}{|c|}{ Reference } \\
\hline Past (any type) & $120 / 39791$ & 3.02 & 1.08 & $(0.89,1.31)$ & 0.440 & 1.04 & $(0.86,1.26)$ & 0.692 & 0.99 & $(0.81,1.20)$ & 0.892 & 0.97 & $(0.80,1.18)$ & 0.768 \\
\hline Current imipramine & $27 / 4691$ & 5.76 & 2.00 & $(1.36,2.93)$ & $<0.001$ & 1.80 & $(1.23,2.65)$ & 0.003 & 1.70 & $(1.16,2.51)$ & 0.007 & 1.66 & $(1.12,2.46)$ & 0.012 \\
\hline $\begin{array}{l}\text { Current selective } \\
\text { serotonin reuptake }\end{array}$ & $88 / 18539$ & 4.75 & 1.69 & $(1.36,2.11)$ & $<0.001$ & 1.35 & $(1.09,1.69)$ & 0.007 & 1.28 & $(1.02,1.60)$ & 0.033 & 1.25 & $(0.99,1.57)$ & 0.061 \\
\hline
\end{tabular}

This article is protected by copyright. All rights reserved 
inhibitors

Current other

$48 / 8711$

5.51

$1.89 \quad(1.42,2.54)$

$<0.001 \quad 1.52 \quad(1.14,2.04)$

0.005

1.40

$(1.04,1.88)$

0.029

$1.35 \quad(1.00,1.84)$

0.052

Current mixed

$7 / 880$

7.96

$2.84 \quad(1.35,5.98)$

$0.006 \quad 2.09 \quad(0.99,4.41)$

0.052

1.85

$(0.87,3.91)$

0.108

$1.82(0.85,3.86)$

HR, hazard ratio.

Analyses with antidepressant use as a three-category variable are based on 63999 women, comprising 377140 person-years, 1124 type 2 diabetes onset.

Analyses with antidepressant use as a six -category variable are based on 63996 women, comprising 377027 person-years, 1124 type 2 diabetes onset.

Antidepressant medication use treated as a time-varying exposure; covariates considered at baseline (2005).

*Model 1: adjusted for age (time scale), marital status, education level and occupational status.

†Model 2: model 1 additionally adjusted for smoking, alcohol consumption, physical activity, BMI, hip circumference and waist circumference.

¥Model 3: model 2 additionally adjusted for severe depressive symptoms, family history of diabetes, hypertension and the number of ambulatory medicine visits in the past 12 months.

$\S$ Model 4: model 3 additionally adjusted for menopausal hormone therapy use, antipsychotic medication use, anxiolytic medication use, hypnotic or sedative medication use.

『Test for homogeneity among different pharmacological classes of current antidepressant.

This article is protected by copyright. All rights reserved 


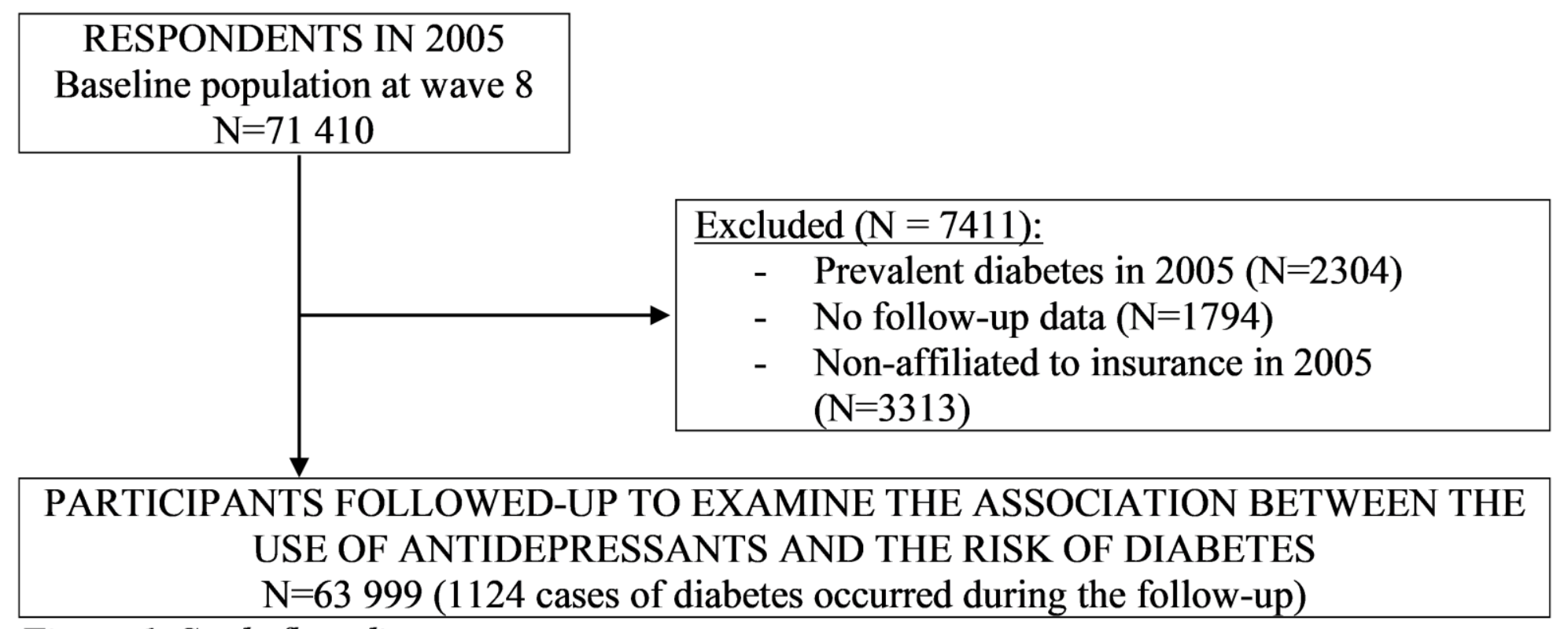

Figure 1. Study flow diagram 